\title{
Two-Stage Dilute Acid Hydrolysis of Dairy Manure for Nutrient Release, Solids Reduction and Reducing Sugar Production
}

\author{
S. K. Yawson, P. H. Liao, K. V. Lo* \\ Department of Civil Engineering, University of British Columbia, Vancouver, Canada. \\ Email: *kvlo@civil.ubc.ca
}

Received July 30 ${ }^{\text {th }}, 2011$; revised August 15 ${ }^{\text {th }}, 2011$; accepted August 22 ${ }^{\text {nd }}, 2011$.

\begin{abstract}
The microwave enhanced advanced oxidation process $\left(\mathrm{MW} / \mathrm{H}_{2} \mathrm{O}_{2}-\mathrm{AOP}\right)$ aided with dilute sulfuric acid was applied in a two-stage treatment of dairy manure for nutrient release, solids reduction, and reducing sugar production. A much higher hydrogen peroxide dosage $\left(1.2 \mathrm{~g} \mathrm{H}_{2} \mathrm{O}_{2} / g\right.$ TS) was used in Stage 2 than that in Stage $1\left(0.38 \mathrm{~g} \mathrm{H}_{2} \mathrm{O}_{2} / g\right.$ TS). Most of the reducing sugar was produced in Stage 1, and only a small amount produced in Stage 2. The highest reducing sugar yield of $15.5 \%$ was obtained at $160^{\circ} \mathrm{C}, 0 \mathrm{~mL} \mathrm{H}_{2} \mathrm{O}_{2}$, and 20 min of heating time. With a high hydrogen peroxide dosage and a higher operating temperature of $160^{\circ} \mathrm{C}$ in Stage 2, the nutrient release conversion rate was much higher in Stage 2 than Stage 1. All of total phosphorus was converted to orthophosphate, and a very high ammonia concentration was obtained in the treated solution. The results indicated that the $\mathrm{MW} / \mathrm{H}_{2} \mathrm{O}_{2}-\mathrm{AOP}$ operated under the reducing process (without hydrogen peroxide) provided the best yield of reducing sugar; however, when operated under an oxidative process (with hydrogen peroxide), it favoured nutrient release and solids disintegration. The concentration of total chemical oxidation demand (TCOD) in the treated solution decreased with an increase of temperature, hydrogen peroxide dosage and heating time. Soluble chemical oxidation demand (SCOD) concentration decreased with a very high hydrogen peroxide dosage. Volatile fatty acids (VFA) concentration decreased with an increase of hydrogen peroxide dosage. Ammonia and orthophosphate concentrations increased with an increase of temperature and hydrogen peroxide dosage.
\end{abstract}

Keywords: Microwave, Advanced Oxidation, Solids Destruction, Reducing Sugar Generation, Nutrient Solubilization

\section{Introduction}

Dairy manure contains fats, proteins, lignin, carbohydrates and inorganic residue, and is rich in a variety of nutrients including nitrogen, phosphorus, and minerals. It is a bio-resource, which can be converted into valuable products, instead of a waste material to be disposed. Carbonaceous matters in dairy manure can be utilized for ethanol, methane and bio-fuel conversion, while nutrients and metals, such as phosphorus, nitrogen, and potassium can be used for struvite production. Lignocellulosic components from dairy manure can be transformed into fermentable saccharides via enzyme, or acid hydrolysis, which can further be converted into ethanol and other valuable products [1]. Lignocellulosic biomass is naturally resistant to breakdown; a pretreatment step, such as the acid hydrolysis is needed for breaking lignin seal and disrupting crystalline structure of cellulose [2,3].
Acid hydrolysis can be achieved with various combinations of acid concentration and operating temperature in a one-stage or a two-stage process. Dilute acid hydrolysis is the most commonly applied process. It is used either as a pretreatment of lignocellulose for subsequent enzyme hydrolysis or as the actual hydrolysis to produce fermentable sugar. In a one-stage acid hydrolysis, acid breaks the matrix structure of the fiber, and polysaccharides are converted into mono sugars [4]. In a two-stage process, dilute acid is used in general in the first stage to solubilize the hemicelluloses, and to reduce cellulose crystallinity. This would effectively remove pentosans prior to the main hydrolysis of cellulose. Concentrated acid ( $12.5 \%$ to $75 \%$ of sulfuric acid concentration) is then used to hydrolyze cellulosic materials to produce mainly glucose in the second-stage process [5]. More sugars can be produced from dairy manure in a two-stage hydrolysis than that from a one-stage hydrolysis procedure [6]. 
Various processes, such as thermal treatment, microwave irradiation (physical treatment), hydrogen peroxide (oxidative) or acid addition (chemical) have been used for treating lignocellulosic biomass. They would decrease the degrees of polymerization and cellulose crystallinity, and would also increase the accessible surface area and pore size of lignocellulosics. As a result, the subsequent enzymatic hydrolysis or acid hydrolysis process for producing fermentable sugar could be enhanced [7-10].

The microwave enhanced advanced oxidation process (MW/ $\mathrm{H}_{2} \mathrm{O}_{2}$-AOP), which uses a combination of microwave irradiations and hydrogen peroxide to produce hydroxyl free radicals to react with organic compounds, has been demonstrated for the production of reducing sugar, as well as the release of soluble materials of nitrogen, phosphorus and minerals from dairy manure $[9,10]$. The effectiveness of the $\mathrm{MW} / \mathrm{H}_{2} \mathrm{O}_{2}$-AOP is depending on operating conditions selected, such as microwave temperature, hydrogen peroxide dosage, microwave intensity, reaction time, and acid concentration. Hydrogen peroxide addition in the $\mathrm{MW} / \mathrm{H}_{2} \mathrm{O}_{2}$-AOP would aid in nutrient solubilization and solids destruction, however, it would be detrimental to the yield of reducing sugar if its dosage is too high. Reducing sugar formed in the process could be further oxidized by hydrogen peroxide to form other oxidation products, such as carbonyl compounds, VFA and $\mathrm{CO}_{2}$ [9]. Both acid concentration and temperature are key factors affecting reducing sugar production [3,7]. A higher reducing sugar production was obtained with acidified dairy manure at $\mathrm{pH} 2$ than at $\mathrm{pH} 4$ [10]. To further examine the effect of acid concentration on the process, reagent grade cellulose fibers was subjected to the $\mathrm{MW} / \mathrm{H}_{2} \mathrm{O}_{2}$-AOP at different sulfuric acid concentrations $(1 \%, 3 \% \& 10 \% \mathrm{v} / \mathrm{v})$, a very low hydrogen peroxide dosage $\left(0.01 \mathrm{~g} \mathrm{H}_{2} \mathrm{O}_{2} / \mathrm{g}\right.$ TS) and at temperature of 120 and $160^{\circ} \mathrm{C}$. The results indicated that the highest reducing sugar production was obtained at sulfuric acid concentration of $3 \%$ [10]. In view of these results, it was concluded that for reducing sugar production as well as nutrient release from dairy manure, the process should be operated at a higher acid concentration, a moderate hydrogen peroxide dosage and a high temperature, preferably more than $120^{\circ} \mathrm{C}$. This study, therefore, was conducted to further investigate the feasibility of using the $\mathrm{MW} / \mathrm{H}_{2} \mathrm{O}_{2}$-AOP in two-stage dilute acid hydrolysis of dairy manure. The objective was to explore operating conditions not only for reducing sugar production, but also for solubilizing nutrients from dairy manure, so that the treated solution could be further utilized for ethanol, bioenergy production and struvite recovery.

\section{Materials and Methods}

\subsection{Apparatus}

A lab-scale Milestone Ethos D Microwave Labstation (Milestone Inc., USA) was used in this study. The system operates at a frequency of 2,450 MHz with a maximum power output of $1000 \mathrm{~W}$. The maximum operating temperature and pressure are $220^{\circ} \mathrm{C}$ and 435 psig, respectively. The system has a real-time temperature controller, and is capable of digesting up to 12 large weight samples at the same time (Model 320, Milestone Inc., USA).

\subsection{Substrate and Sample Preparation}

Dairy manure was obtained from the Dairy Education \& Research Centre, University of British Columbia at Agassiz, British Columbia, Canada. Only the solids portion, obtained after the liquid-solids separation (L/S) was used in this study. Dairy manure diluted with distilled water to give $5.4 \%$ total solids (TS) was used as the substrate for the first stage acid hydrolysis (Stage 1). The manure initially had a SCOD concentration of $5.7 \pm 1.0 \mathrm{~g} / \mathrm{L}$, TCOD of $66.0 \pm 6.6 \mathrm{~g} / \mathrm{L}$, total phosphorus (TP) of $355 \pm 21$ $\mathrm{mg} / \mathrm{L}$, orthophosphate of $48 \pm 1.0 \mathrm{mg} / \mathrm{L}$, total Kjeldahl nitrogen (TKN) of $1420 \pm 60 \mathrm{mg} / \mathrm{L}$, ammonia of $92 \pm 2.4$ $\mathrm{mg} / \mathrm{L}$ and reducing sugar of $898 \pm 415 \mathrm{mg} / \mathrm{L}$, respectively. The remaining solids from Stage 1 were used as the substrate for the second stage acid hydrolysis (Stage 2). For Stage 2, the solids were obtained by centrifuging the treated sample from Stage 1 at $4000 \mathrm{rpm}$, decanting the soluble portion and oven drying the solids at $40^{\circ} \mathrm{C}$.

\subsection{Sample Analysis}

Dairy manure samples were centrifuged at $3500 \mathrm{rpm}$ for 10 minutes, and the supernatant was extracted for analysis of SCOD, orthophosphate, soluble ammonia, VFA and reducing sugar. All of the chemical analyses, except that of reducing sugar, followed the procedures outlined in Standard Methods [11]. The colorimetric method was employed to determine the total reducing sugar content using anthrone reagent [12]. For orthophosphate analysis, dairy manure samples were determined at $0.5 \%$ TS to ensure correct measurement [13]. The initial dairy manure samples were also analyzed for TS, TCOD, TP and TKN. All chemical analyses, except TS and COD, were determined by a flow injection system, (Lachat QuikChem 8000 Automatic Ion Analyzer, Lachat Instruments, USA). A Hewlett Packard 6890 Series II gas chromatograph, equipped with a flame ionization detector (FID), was used to measure VFA. Volatile separation was accomplished with an HP FFAP (free fatty acid phase) column $(0.25 \mathrm{~m} \times 0.31 \mathrm{~mm}$ with $0.52 \mu$ film thickness). The in- 
jection temperature was set at $175^{\circ} \mathrm{C}$ and the flame ionization detector was at $250^{\circ} \mathrm{C}$. Helium was the carrier gas at a head pressure of $69 \mathrm{kPa}$.

\subsection{Experimental Design}

Based on the results obtained from previous studies, an acid concentration of $3 \%$ and a relatively moderate hydrogen peroxide concentration were selected for Stage 1 [9,10]. Acidified dairy manure $\left(3 \%\right.$ of $\mathrm{H}_{2} \mathrm{SO}_{4}, 30 \mathrm{~mL}$ each) was treated at two heating temperatures (120 and $160^{\circ} \mathrm{C}$ ), two heating times (20 and $60 \mathrm{~min}$ ), and $\mathrm{H}_{2} \mathrm{O}_{2}$ dosages of 0 and $2.0 \mathrm{~mL}\left(0\right.$ and $0.38 \mathrm{~g} \mathrm{H}_{2} \mathrm{O}_{2} / \mathrm{g}$ TS). A total of eight experimental sets, each with six replicates were performed in Stage 1 (Table 1). The rate of temperature increase for all the experiments was set at $20^{\circ} \mathrm{C}$ per minute up to the designated treatment temperature and subsequently held for the specified time period.

Following the microwave treatment, solids remaining from each sample from Stage 1 were dried and used as the substrate for the second stage (Stage 2). For Stage 2, $0.5 \mathrm{~g}$ of solids residue was dissolved in $30 \mathrm{~mL}$ of $3 \%$ sulfuric acid solution, this was calculated as of $1.7 \%$ TS in the solution. A heating temperature of $160^{\circ} \mathrm{C}$, and heating time of 5 minutes were selected to facilitate the breakdown of dairy manure fibers. Solids previously treated at $0 \mathrm{~mL} \mathrm{H}_{2} \mathrm{O}_{2}$ in Stage 1 were treated at $0 \mathrm{~mL}$ $\mathrm{H}_{2} \mathrm{O}_{2}$ in Stage 2; similarly, substrates treated at $2 \mathrm{~mL}$ $\mathrm{H}_{2} \mathrm{O}_{2}$ in Stage 1 were treated at $2 \mathrm{~mL} \mathrm{H}_{2} \mathrm{O}_{2}$ in Stage 2 (Table 1). A much higher hydrogen peroxide dosage (1.2 $\mathrm{g}_{2} \mathrm{O}_{2} / \mathrm{g}$ TS) was used in Stage 2 than that in Stage 1. There were six replicates in each set of experiments.

\section{Results and Discussion}

\subsection{Stage 1 Acid Hydrolysis}

\subsubsection{Reducing Sugar Production}

The effects of temperature, heating time and hydrogen peroxide dosage on reducing sugar production are shown in Table 2 and Figure 1. When heating time and dosage were maintained constant, the yield of reducing sugar did not increase with an increase of temperature from $120^{\circ} \mathrm{C}$ to $160^{\circ} \mathrm{C}$. When the temperature was maintained constant, reducing sugar concentrations decreased with an increase of heating time. A higher yield of reducing sugar was obtained at no hydrogen peroxide (Figure 1). In the presence of hydrogen peroxide, however, its yield decreased, as the reducing sugar produced were further oxidized or decomposed. The higher temperature also favored further oxidation reactions with the presence of hydrogen peroxide, resulting in a lower reducing sugar yield. The highest reducing sugar yield of $15.5 \%$ was obtained at $120^{\circ} \mathrm{C}, 0 \mathrm{~mL} \mathrm{H}_{2} \mathrm{O}_{2}$, and $20 \mathrm{~min}$ of heating time (Table 2). This was the highest reducing sugar yield in the $\mathrm{MW} / \mathrm{H}_{2} \mathrm{O}_{2}$-AOP applications conducted in our laboratory $[9,10]$. The yield of reducing sugar was similar to the results with the conventional heating process reported by Liao, et al. [1]. When raw dairy manure was treated with $3 \%$ sulfuric acid at conventional heating for 1 hour, the yield was $12.28 \mathrm{~g}$ reducing sugar/g manure. They also reported that the yield was very low at temperatures below $110^{\circ} \mathrm{C}$, and a slight increase of the yield was obtained with an increase of temperatures. The yield did not increase at acid concentrations more than 3\%, while a very low yield of reducing sugar produced at an acid concentration of $1 \%$. Reducing sugars produced from their study were mainly arabinose, galactose and xylose. This indicated that hemicelluloses were solubilized, and degraded into pentose under dilute acid concentration, and the residue solids were mainly cellulosics [5]. Liao, et al. also stated that the conversion rate of cellulose and hemicellulose to sugar from dairy manure was very low under dilute acid and low temperatures [14]. For the $\mathrm{MW} / \mathrm{H}_{2} \mathrm{O}_{2}$-AOP, acid concentration, heating time and temperature, as well as interaction among all three factors, affected reducing sugar yield from dairy manure. The trend and the factors affecting reducing sugar production for the $\mathrm{MW} / \mathrm{H}_{2} \mathrm{O}_{2}$-AOP were also consistent with the previous studies $[9,10]$.

\subsubsection{Nutrient Release and Solids Disintegration}

The results of nutrient release and solid disintegration are shown in Table 2. More ammonia and orthophosphate were solubilized at $160^{\circ} \mathrm{C}$ than at $120^{\circ} \mathrm{C}$ (Figures 2 and 3). As high as $195 \%$ increase for ammonia and $307 \%$ for orthophosphate were obtained at $160^{\circ} \mathrm{C}, 2 \mathrm{~mL}$ of $\mathrm{H}_{2} \mathrm{O}_{2}$ and heating time of $60 \mathrm{~min}$ (Set 8). Up to $13 \%$ of the TKN and $41 \%$ of the TP were released as ammonia and orthophosphate, respectively. The lowest percentage increases for both ammonia and orthophosphate were obtained at $120^{\circ} \mathrm{C}, 0 \mathrm{~mL} \mathrm{H}_{2} \mathrm{O}_{2}$ and heating time of $20 \mathrm{~min}$ (Set 1 ). The combined effects of temperature and time also resulted in more nutrients being released. Higher hydrogen peroxide dosages increased the amount of ammonia and orthophosphate in solution (Figures 2 and 3). Hydrogen peroxide dosage affected more on ammonia release than on orthophosphate release. Therefore, the significant factors affecting ammonia release were temperature and hydrogen peroxide dosage, while temperature was the most significant factor affecting orthophosphate release. To a lesser extent, heating time also affected orthophosphate and ammonia release. Hydrogen peroxide dosage was detrimental to the yield of reducing sugar, but it did help solubilize phosphorus and ammonia. The results were consistent with the findings of previous studies $[9,10,15]$.

The yield of ammonia and orthophosphate from this 
Table 1. Experimental design.

\begin{tabular}{|c|c|c|c|c|c|}
\hline Stage & Set no. & TS (\%) & Temperature $\left({ }^{\circ} \mathrm{C}\right)$ & $\mathrm{H}_{2} \mathrm{O}_{2}$ dosage $(\mathrm{mL})$ & Heating time (min) \\
\hline \multirow[t]{8}{*}{1} & 1 & 5.4 & 120 & 0 & 20 \\
\hline & 2 & 5.4 & 120 & 2 & 20 \\
\hline & 3 & 5.4 & 120 & 0 & 60 \\
\hline & 4 & 5.4 & 120 & 2 & 60 \\
\hline & 5 & 5.4 & 160 & 0 & 20 \\
\hline & 6 & 5.4 & 160 & 2 & 20 \\
\hline & 7 & 5.4 & 160 & 0 & 60 \\
\hline & 8 & 5.4 & 160 & 2 & 60 \\
\hline \multirow[t]{8}{*}{2} & 1 & 1.7 & 160 & 0 & 5 \\
\hline & 2 & 1.7 & 160 & 2 & 5 \\
\hline & 3 & 1.7 & 160 & 0 & 5 \\
\hline & 4 & 1.7 & 160 & 2 & 5 \\
\hline & 5 & 1.7 & 160 & 0 & 5 \\
\hline & 6 & 1.7 & 160 & 2 & 5 \\
\hline & 7 & 1.7 & 160 & 0 & 5 \\
\hline & 8 & 1.7 & 160 & 2 & 5 \\
\hline
\end{tabular}

Table 2. Overview of results for first stage of acid hydrolysis.

\begin{tabular}{|c|c|c|c|c|c|c|c|c|c|c|c|c|}
\hline $\begin{array}{l}\text { Set } \\
\text { no. }\end{array}$ & Sugar (mg/L) & $\begin{array}{l}\text { Sugar } \\
\text { (\% TS) }\end{array}$ & ;COD (g/L) & $\begin{array}{c}\text { SCOD } \\
\text { increase } \\
(\%)\end{array}$ & $\begin{array}{c}\text { TCOD } \\
(\mathrm{g} / \mathrm{L})\end{array}$ & $\begin{array}{c}\text { VFA } \\
(\mathrm{mg} / \mathrm{L})\end{array}$ & $\begin{array}{c}\text { TKN } \\
(\mathrm{mg} / \mathrm{L})\end{array}$ & $\begin{array}{l}\mathrm{NH}_{4}-\mathrm{N} \\
(\mathrm{mg} / \mathrm{L})\end{array}$ & $\begin{array}{c}\mathrm{NH}_{4}-\mathrm{N} \\
\text { increase } \\
(\%)\end{array}$ & $\mathrm{TP}(\mathrm{mg} / \mathrm{L})$ & $\begin{array}{l}\mathrm{PO}_{4}-\mathrm{P} \\
(\mathrm{mg} / \mathrm{L})\end{array}$ & $\begin{array}{c}\mathrm{PO}_{4}-\mathrm{P} \\
\text { increase } \\
(\%)\end{array}$ \\
\hline 1 & $8150 \pm 996$ & 15.1 & $21.4 \pm 1.6$ & 277 & $59.7 \pm 9.4$ & $1489 \pm 131$ & $1117 \pm 107$ & $140 \pm 9$ & 53 & $260 \pm 14$ & $128 \pm 2$ & 169 \\
\hline 2 & $3806 \pm 745$ & 7.0 & $22.4 \pm 1.7$ & 293 & $57.2 \pm 4.4$ & $970 \pm 244$ & $1187 \pm 46$ & $208 \pm 6$ & 126 & $248 \pm 5$ & $140 \pm 7$ & 195 \\
\hline 3 & $5032 \pm 723$ & 9.3 & $21.9 \pm 1.0$ & 284 & $68.3 \pm 4.4$ & $962 \pm 241$ & $1250 \pm 87$ & $148 \pm 8$ & 61 & $265 \pm 7$ & $132 \pm 5$ & 178 \\
\hline 4 & $3690 \pm 880$ & 6.8 & $23.0 \pm 0.6$ & 304 & $65.2 \pm 9.0$ & $697 \pm 266$ & $1165 \pm 23$ & $224 \pm 10$ & 144 & $242 \pm 5$ & $148 \pm 10$ & 211 \\
\hline 5 & $8356 \pm 2987$ & 15.5 & $28.2 \pm 0.8$ & 396 & $73.0 \pm 8.1$ & $687 \pm 150$ & $1194 \pm 55$ & $172 \pm 10$ & 87 & $254 \pm 6$ & $171 \pm 7$ & 259 \\
\hline 6 & $5124 \pm 519$ & 9.5 & $30.9 \pm 1.7$ & 444 & $67.1 \pm 3.7$ & $319 \pm 158$ & $1163 \pm 7$ & $254 \pm 11$ & 176 & $254 \pm 8$ & $180 \pm 9$ & 279 \\
\hline 7 & $4801 \pm 597$ & 8.9 & $28.4 \pm 1.5$ & 398 & $63.0 \pm 7.7$ & $414 \pm 239$ & $1206 \pm 91$ & $209 \pm 43$ & 127 & $259 \pm 12$ & $192 \pm 6$ & 305 \\
\hline 8 & $2538 \pm 631$ & 4.7 & $28.0 \pm 3.3$ & 391 & $62.7 \pm 8.1$ & $291 \pm 63$ & $1028 \pm 45$ & $271 \pm 49$ & 195 & $237 \pm 9$ & $194 \pm 9$ & 307 \\
\hline
\end{tabular}

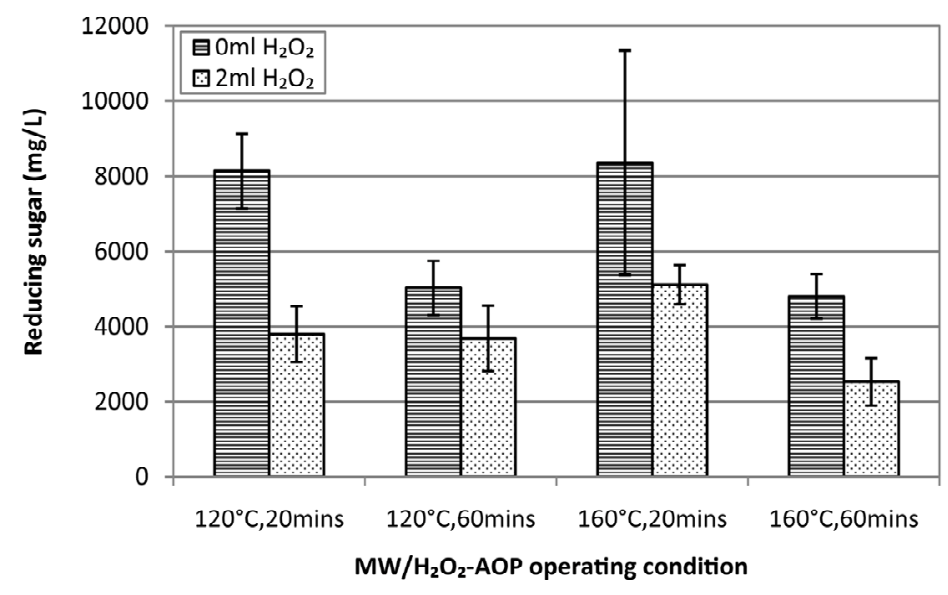

Figure 1. Reducing sugar produced from first stage of acid hydrolysis. 


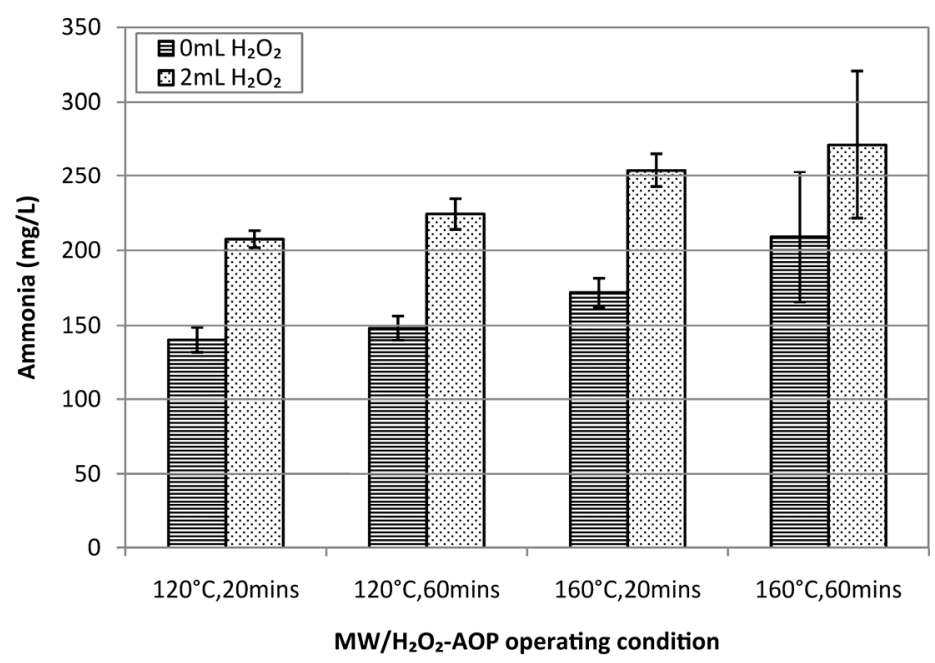

Figure 2. Ammonia release from first stage of acid hydrolysis.

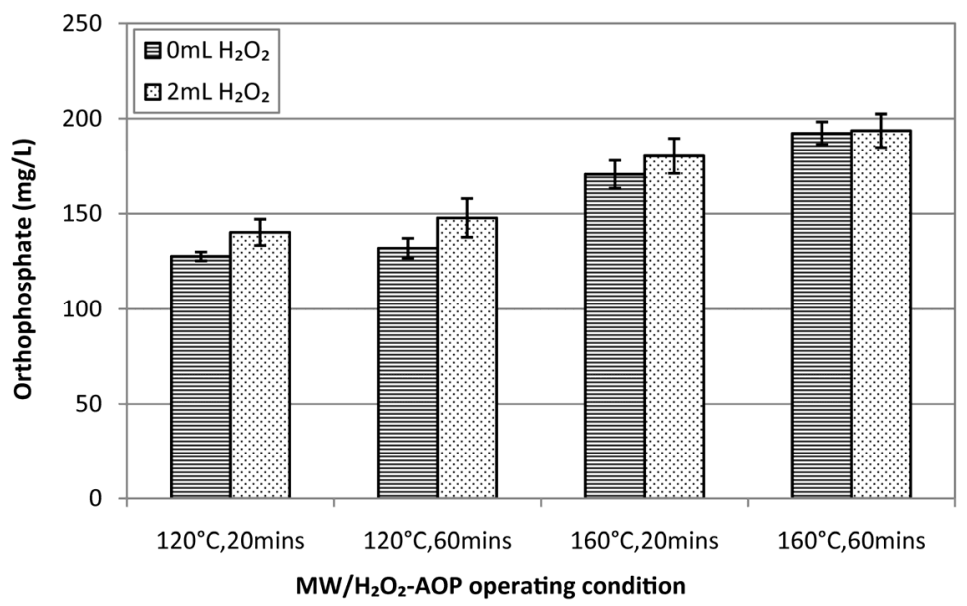

Figure 3. Orthophosphate release from first stage of acid hydrolysis.

study was comparable to the results reported by other groups [16,17]. Similarly, the release of $20 \%$ - $40 \%$ soluble phosphorus and $9 \%$ - 14\% ammonia were reported with microwave-based thermochemical treatment of dairy manure [17]. Pan et al., [16] however, reported that the $\mathrm{MW} / \mathrm{H}_{2} \mathrm{O}_{2}$-AOP process could achieve up to $85 \%$ of total phosphate release from dairy manure filtrate at $120^{\circ} \mathrm{C}$. This was due to the fact that a very high hydrogen peroxide dosage was applied in their study.

The $\mathrm{MW} / \mathrm{H}_{2} \mathrm{O}_{2}$-AOP not only solubilizes phosphorus and ammonia, but also reduces total suspended solids (TSS) [15]. The concentration of SCOD increased with an increase of temperature as showed in Figure 4. The SCOD could further be oxidized and/or decomposed into $\mathrm{CO}_{2}$ at a higher temperature and a longer reaction time, therefore, its concentration decreased as shown in Set 8 $\left(160^{\circ} \mathrm{C}, 2 \mathrm{~mL}\right.$ of $\mathrm{H}_{2} \mathrm{O}_{2}$ and reaction time of $60 \mathrm{~min}$.
VFA existed mainly as acetic acid, and with some propionic, butyric and heptanoic acids. Highest VFA release was at $120^{\circ} \mathrm{C}, 0 \mathrm{~mL}$ of $\mathrm{H}_{2} \mathrm{O}_{2}$ and a reaction time of 20 min. VFA concentration decreased with an increase of temperature, hydrogen peroxide dosage and reaction time (Figure 5). The decrease in VFAs with a higher temperature and a longer reaction time could be due to either vaporization of VFAs or oxidation to $\mathrm{CO}_{2}$ generation as the end product [15].

\subsection{Stage 2 Acid Hydrolysis}

The results of Stage 2 of acid hydrolysis are shown in Table 3; up to $4 \%$ of additional reducing sugar could be obtained. The higher reducing sugar yield was obtained in the process without adding hydrogen peroxide (Figure 6). It was not very effective in producing reducing sugar in the second stage of acid hydrolysis, with a short reac- 


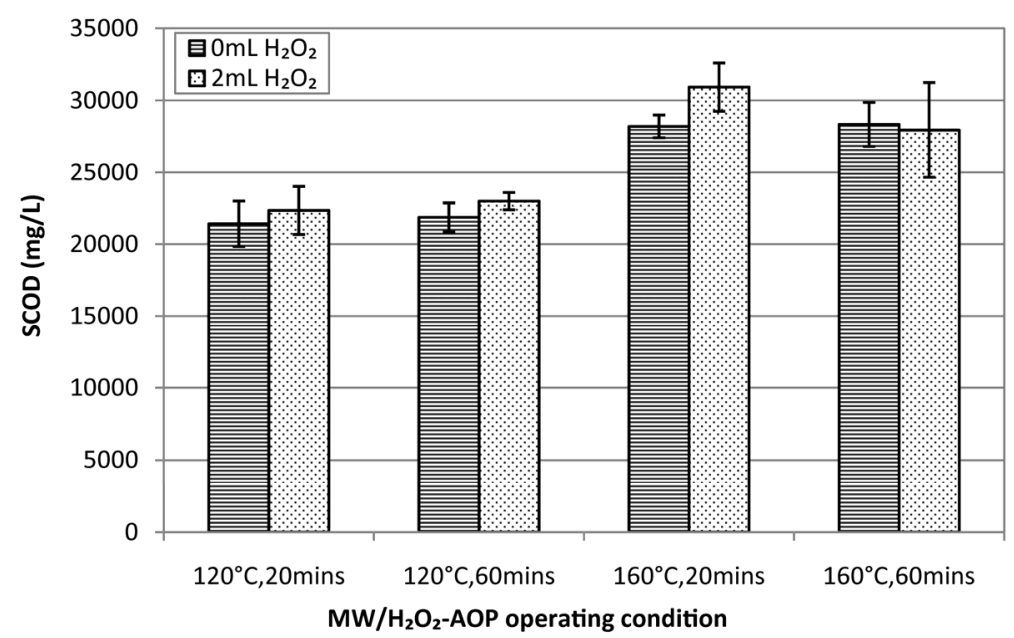

Figure 4. SCOD release from first stage of acid hydrolysis.

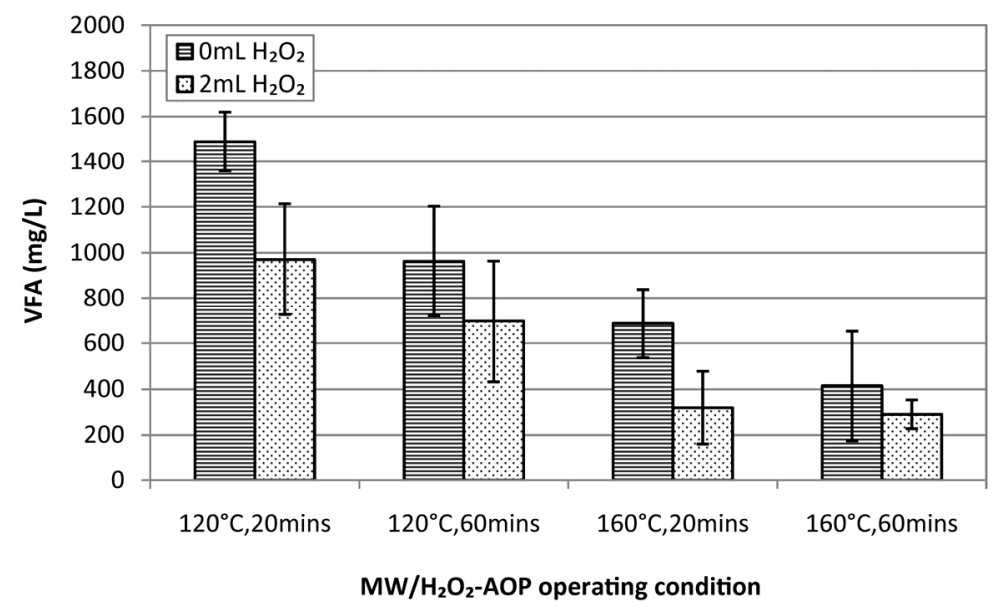

Figure 5. VFA release from first stage of acid hydrolysis.

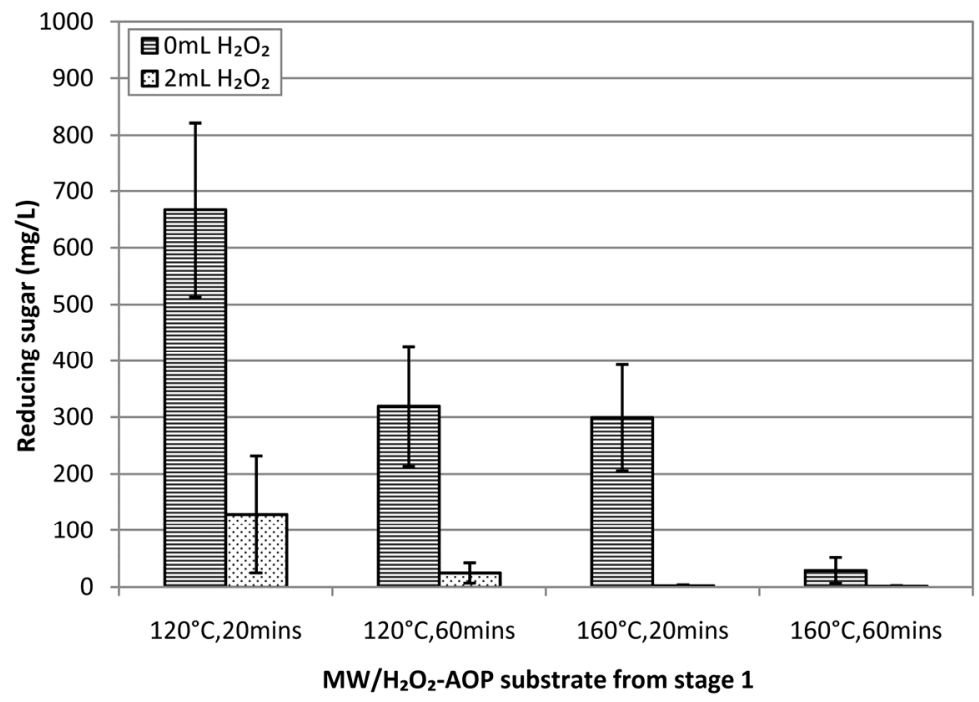

Figure 6. Reducing sugar yield from second stage of acid hydrolysis. 
Table 3. Overview of results for second stage of acid hydrolysis.

\begin{tabular}{|c|c|c|c|c|c|c|c|c|c|}
\hline Set no. & Sugar (mg/L) & $\begin{array}{l}\text { Sugar yield } \\
\text { (\% of TS) }\end{array}$ & SCOD (g/L) & TCOD (g/L) & VFA (mg/L) & TKN (mg/L) & $\begin{array}{l}\mathrm{NH}_{4}-\mathrm{N} \\
(\mathrm{mg} / \mathrm{L})\end{array}$ & TP (mg/L) & $\begin{array}{l}\mathrm{PO}_{4}-\mathrm{P} \\
(\mathrm{mg} / \mathrm{L})\end{array}$ \\
\hline 1 & $667 \pm 154$ & 4 & $2.6 \pm 0.3$ & $14.9 \pm 0.1$ & $26 \pm 1$ & $193 \pm 22$ & $35 \pm 3$ & $20 \pm 2$ & $20 \pm 1$ \\
\hline 2 & $129 \pm 104$ & 0.77 & $1.7 \pm 0.6$ & $11.2 \pm 0.3$ & $200 \pm 89$ & $176 \pm 14$ & $126 \pm 3$ & $19 \pm 2$ & $25 \pm 2$ \\
\hline 3 & $319 \pm 106$ & 1.91 & $2.1 \pm 0.4$ & $16.4 \pm 0.5$ & $51 \pm 35$ & $156 \pm 25$ & $26 \pm 2$ & $22 \pm 4$ & $23 \pm 2$ \\
\hline 4 & $25 \pm 18$ & 0.15 & $1.0 \pm 0.2$ & $13.7 \pm 0.3$ & $125 \pm 49$ & $151 \pm 22$ & $131 \pm 5$ & $20 \pm 2$ & $26 \pm 2$ \\
\hline 5 & $299 \pm 94$ & 1.79 & $1.9 \pm 0.2$ & $24.8 \pm 0.3$ & $21 \pm 0$ & $137 \pm 21$ & $27 \pm 2$ & $20 \pm 2$ & $23 \pm 1$ \\
\hline 6 & $2 \pm 1.7$ & 0.01 & $0.9 \pm 0.3$ & $19.8 \pm 0.5$ & $93 \pm 27$ & $177 \pm 20$ & $112 \pm 7$ & $20 \pm 1$ & $23 \pm 2$ \\
\hline 7 & $29 \pm 23$ & 0.18 & $0.8 \pm 0.0$ & $19.9 \pm 0.2$ & $0 \pm 0$ & $173 \pm 7$ & $31 \pm 1$ & $24 \pm 2$ & $29 \pm 9$ \\
\hline 8 & $1.5 \pm 1.0$ & 0.01 & $0.8 \pm 0.0$ & $16.9 \pm 0.2$ & $98 \pm 20$ & $180 \pm 5$ & $114 \pm 7$ & $21 \pm 2$ & $26 \pm 2$ \\
\hline
\end{tabular}

tion time of five minutes, even at $160^{\circ} \mathrm{C}$. A low reducing sugar yield was also due to very high hydrogen peroxide dosage used in this stage $\left(1.2 \mathrm{~g} \mathrm{H}_{2} \mathrm{O}_{2} / \mathrm{g}\right.$ TS). As reported earlier in Stage 1, a high hydrogen peroxide dosage favors further oxidation process, as a result, it decreases reducing sugar yield. The other reason was probably due to the inherent characteristic of dairy manure; a high nitrogen content and crystallinity of lignocelluloses in dairy manure [14]. A high conversion rate of reducing sugar could only be obtained with very high acid concentrations wherein both hemicelluloses and cellulose could be converted after decrystallization pretreatment [14]. In order to achieve a much higher reducing sugar yield from the residue solids obtained from Stage 1, a much higher acid concentrations and/or a longer reaction time need to be used in Stage 2 .

Hydrogen peroxide addition favored the release of nutrients and solids disintegration from diary manure (Table 3). Due to the high hydrogen peroxide dosage of 1.2 $\mathrm{g} \mathrm{H}_{2} \mathrm{O}_{2} / \mathrm{g}$ TS, very high percentage of ammonia solubilization, ranging from $63 \%$ to $86 \%$ was obtained. Low soluble ammonia concentrations were for those sets without hydrogen peroxide addition (Figure 7). A high yield of ammonia occurred at high microwave temperature of $160^{\circ} \mathrm{C}$ and with $\mathrm{H}_{2} \mathrm{O}_{2}$; this was consistent with findings of previous studies $[9,10]$. Phosphorus was completely solublized into solution, with or without hydrogen peroxide (Figure 8). Temperature was the most significant factor affecting orthophosphate release. The solubilization of COD and formation of VFAs were influenced to a large extent by hydrogen peroxide dosage (Table 3). The presence of hydrogen peroxide resulted in less amounts of SCOD in the solution (Figure 9). This could be due to the conversion of all soluble organics in the substrate to $\mathrm{CO}_{2}$ at the higher temperatures of $160^{\circ} \mathrm{C}$. TCOD concentration in the treated solution was much less for the sets with hydrogen peroxide than those without. This was also an indication of $\mathrm{CO}_{2}$ formation as the end product in the process. Solid residues previously treated (Stage 1) at lower temperatures $\left(120^{\circ} \mathrm{C}\right)$ and shorter heating times (20 min) released more SCOD compared to residues previously treated at higher temperatures $\left(160^{\circ} \mathrm{C}\right)$ and longer heating times $(60 \mathrm{~min})$. The presence of hydrogen peroxide resulted in an increase of VFAs. There were no clear trends for the release of VFA with respect to heating time (Figure 10).

The trend for nutrient release and solids disintegration for Stage 2 were similar to that of Stage 1 . Due to the very high hydrogen peroxide dosage in Stage 2, a much lower reducing sugar yield was produced. However, a much higher yield of both soluble ammonia and orthophosphate was obtained. It is therefore recommended that the $\mathrm{MW} / \mathrm{H}_{2} \mathrm{O}_{2}$-AOP should be operated under the reducing process for the production of reducing sugar, and under the oxidative process for the solubilization of nutrients and solid disintegration.

\section{Conclusions}

The $\mathrm{MW} / \mathrm{H}_{2} \mathrm{O}_{2}$-AOP can be an effective method in treating dairy manure for nutrient release, solids reduction and reducing sugar production, even with a very low acid concentration of $3 \%$.

For reducing sugar production, the $\mathrm{MW} / \mathrm{H}_{2} \mathrm{O}_{2}$-AOP should be operated under a reducing process (without hydrogen peroxide). Almost all of the reducing sugar was converted in Stage 1, and only a small amount of additional reducing sugar was produced in Stage 2.

With a high hydrogen peroxide dosage and a higher operating temperature of $160^{\circ} \mathrm{C}$ in Stage 2, the nutrient release conversion rate was much higher in Stage 2 in than Stage 1. All of total phosphorus was converted to orthophosphate, and a very high ammonia concentration was obtained in the treated solution. For nutrient release and solids disintegration, the $\mathrm{MW} / \mathrm{H}_{2} \mathrm{O}_{2}$-AOP should be operated under an oxidative process (with hydrogen peroxide) to have the best result. 


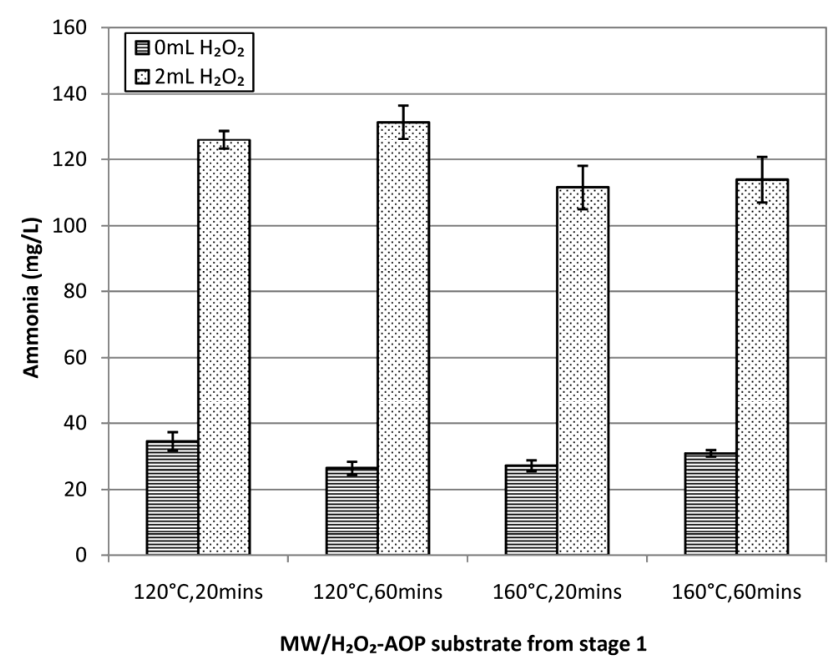

Figure 7. Reducing sugar yield from second stage of acid hydrolysis.

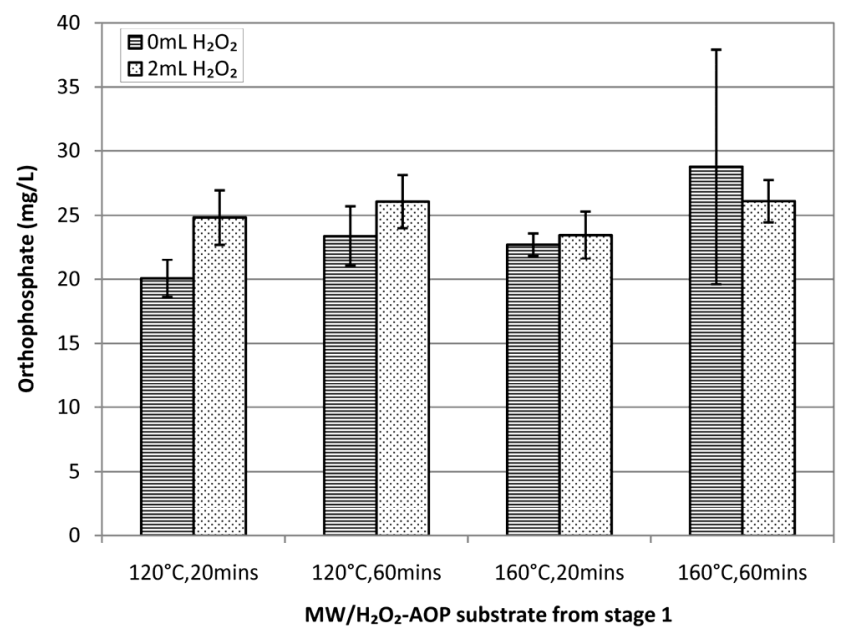

Figure 8. Orthophosphate yield from second stage of acid hydrolysis.

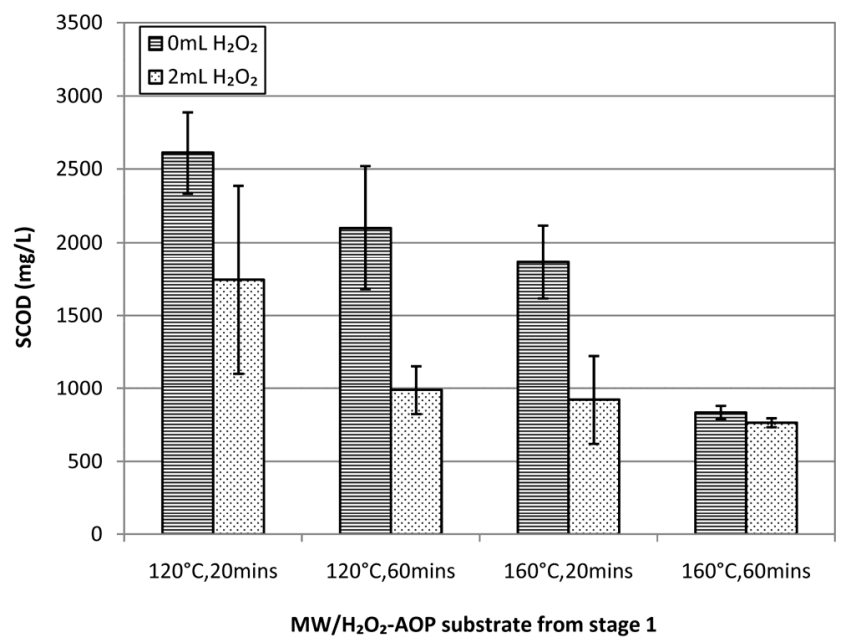

Figure 9. SCOD yield from second stage of acid hydrolysis. 


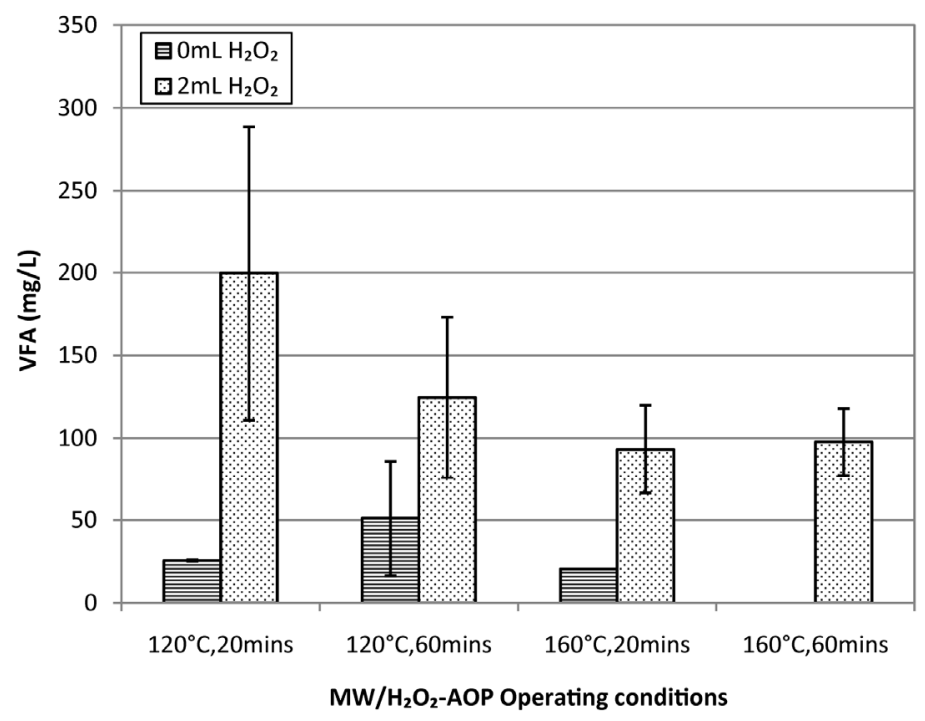

Figure 10. VFA yield from second stage of acid hydrolysis.

\section{Acknowledgements}

The authors wish to acknowledge research funding from the Natural Science and Engineering Research Council of Canada (NSERC).

\section{REFERENCES}

[1] W. Liao, Y. Liu, C. Liu and S. Chen, “Optimizing Dilute Acid Hydrolysis of Hemicelluloses in a Nitrogen-Rich Cellulosic Material-Dairy Manure,” Bioresource Technology, Vol. 94, No. 1, 2004, pp. 33-41. doi:10.1016/j.biortech.2003.11.011

[2] C. E. Wyman, "Ethanol from Lignocellulosic Biomass: Technology, Economics, and Opportunities,” Bioresource Technology, Vol. 50, No. 1, 1994, pp. 3-16. doi:10.1016/0960-8524(94)90214-3

[3] Y. Sun and J. Cheng, "Hydrolysis of Lignocellulosic MaTerials for Ethanol Production: A Review,” Bioresource Technology, Vol. 83, No. 1, 2002, pp. 1-11. doi:10.1016/S0960-8524(01)00212-7

[4] N. Mosier, C. Wyman, B. Dale, R. Elander, Y. Y. Lee, M. Holtzapple and M. Ladisch, "Features of Promising Technologies for Pretreatment of Lignocellulosic Biomass," Bioresource Technology, Vol. 96, No. 6, 2005, pp. 673686. doi:10.1016/j.biortech.2004.06.025

[5] W. Liao, Z. Wen, S. Hurley, Y. Liu, C. Liu and S. Chen, "Effects of Hemeicellulose and Lignin on Enzyme HydroLysios of Cellulose from Dairy Manure," Applied Biochemistry and Biotechnology, Vol. 124, No. 1-3, 2005, pp. 1017-1030. doi:10.1385/ABAB:124:1-3:1017

[6] S. Chen, Z. Wen, W. Liao, C. Liu, R. L. Kincaid, J. H. Harrison, D. C. Elliot, M. D. Brown and D. J. Stevens, "Studies into Using Manure in a Biorefinery Concept,” Applied Biochemistry and Biotechnology, Vol. 124, No. 1-3, 2005, pp. 999-1015. doi:10.1385/ABAB:124:1-3:0999
[7] M. J. Taherzadeh and K. Karimi, "Pretreatment of Lignocellulosic Wastes to Improve Ethanol and Biogas Production: A Review," International Journal of Molecular Sciences, Vol. 9, No. 9, 2008, pp. 1621-1651. doi:10.3390/ijms9091621

[8] A. T. W. Hendriks and G. Zeeman, "Pretreatments to Enhance the Digestibility of Lignocellulosic Biomass," Bioresource Technology, Vol. 100, No. 1, 2009, pp. 10-18.

[9] A. Kenge, "Enhancing Nutrient Solubilization from Organic Waste Using the Microwave Technology,” MASc Thesis, University of British Columbia, Vancouver, 2008.

[10] S. K. Yawson, "Dairy Manure Treatment Using SolidLiquid Separation and Microwave Enhanced Advanced Oxidation Process,” MASc Thesis, University of British Columbia, Vancouver, 2010.

[11] American Public Health Association, "Standard Methods for the Examination of Water and Wastewater" 20th Edition, American Public Health Association, Washington, DC, 1998.

[12] K. Raunkjaer, T. Hvitved-Jacobsen and P. H. Nielsen, "Measurement of Pools of Protein, Carbohydrate and Lipid in Domestic Wastewater,” Water Research, Vol. 28, No. 2, 1994, pp. 251-262. doi:10.1016/0043-1354(94)90261-5

[13] A. M. Wolf, P. A. Kleinman, A. N. Sharpley and D. B. Beegle, "Development of a Water-Extractable Phosphorus Test for Manure: An Interlaboratory Study,” Soil Sci. Soc. Am., Vol. 69, No. 3, 2005, pp. 695-700. doi:10.2136/sssaj2004.0096

[14] W. Liao, Y. Liu, C. Liu, Z. Wen and S. Chen, "Acid Hydrolysis of Fibers from Dairy Manure,” Bioresource Technology, Vol. 97, No. 14, 2006, pp. 1687-1695. doi:10.1016/j.biortech.2005.07.028

[15] A. Qureshi, K. V. Lo and P. H. Liao, "Microwave Treatment and Struvite Recovery Potential of Dairy Manure," Journal of Environmental Science and Health Part B, Vol. 
43, No. 4, 2008, pp. 350-357.

doi:10.1080/03601230801941709

[16] S. H. Pan, K. V. Lo, P. H. Liao and H. Schreier, "Microwave Pretreatment for enhancement of Phosphorus Release from Dairy Manure,” Journal of Environmental Science and Health Part B, Vol. 41, No. 4, 2006, pp. 451-458. doi:10.1080/03601230600619068

[17] Y. Jin, Z. Hu and Z. Wen, "Enhancing Anaerobic Digestibility and Phosphorus Recovery of Dairy Manure Through Microwave-Based Thermochemical Pretreatment," Water Research, Vol. 43, No. 14, 2009, pp. 3493-3502.

doi:10.1016/j.watres.2009.05.017 